\title{
Evaluation of time response of GMS for soil suction measurement
}

\author{
Danilo L. Vettorello ${ }^{1 *}$, and Fernando A. M. Marinho. ${ }^{2}$ \\ ${ }^{1}$ Universidade de São Paulo, Instituto de Geociências, São Paulo, Brazil \\ ${ }^{2}$ Universidade de São Paulo, Instituto de Geociências, Departamento de Geologia Sedimentar e Ambiental, São Paulo, Brazil
}

\begin{abstract}
The Granular Matrix Sensor (GMS) is an indirect method for soil suction measurement. Since GMS is comparatively inexpensive, robust and usually provide continuous soil suction data, it is a natural candidate for civil engineering practice. The sensor has been used mainly for irrigation purposes, and also for some civil engineering activities. Questions about its effectiveness and reliability are still posed, making studies about this topic desirable. This study presents a laboratory comparison between Watermark and an ordinary tensiometer during an equilibrium period and for a wetting procedure performed in a compacted sandy silt soil (residual soil of gneiss). The results yielded that GMS may provide tensiometer equivalent suction values in a context of no significant water content variation. However, it takes a longer time to obtain stabilized suction values. During the wetting procedure, GMS presented a delay of about $2 \mathrm{~h}$ in detecting water while tensiometer detection was almost instantaneous.
\end{abstract}

\section{Introduction}

Methodologies for in situ suction measurement have been one of the challenges for an extensive use of unsaturated soil mechanics concepts for practical purposes (Fredlund 2006 [1]). Besides the development of more sophisticated equipment, such as the high capacity tensiometer (Ridley \& Burland 1993 [2]), simpler and more precise methods are still needed for the popularization of suction monitoring routines of medium to long-term civil engineering works, such as cuts, dams and roads. One candidate to meet this need is the Granular Matrix Sensor (GMS), an equipment traditionally used during agricultural routines for measuring soil suction $(\psi)$.

The GMS uses soil electrical resistivity $(\Omega)$ to infer soil suction. It consists of an electrode embedded in a granular matrix surrounded by a synthetic membrane held in a stainless-steel case. When the sensor is buried in the soil, it equilibrates in terms of pore water pressure with it and, as a consequence, the soil suction can be inferred indirectly by the electrical resistivity. As can be presumed, temperature and water salinity are factors that may affect the GMS operation capacity (Jovanovic \& Annandale 1997 [3]).

The GMS used in this study is the Watermark 200SS (Irrometer Co. Riverside, CA, USA). The $\Omega$ measured by Watermark is converted into suction by means of a calibration function. For Watermark model 200SS, the default calibration function is that proposed by Shock et al. (1998) [4] at a temperature (T) of $24^{\circ} \mathrm{C}$, as indicated by the supplier (www.irrometer.com/200ss.html).
The critics of Watermark 200SS in estimating soil suction, as well as for its previous model (Watermark 200), orbit two main points. The first one is its time response, which tends to be slow when considering events of rapid drying or partial rewetting of the soil (e.g. McCann et al. 1992 [5]; Ley et al. 2004 [6]; MuñozCarpena et al. 2005 [7]; Thompson et al. 2006 [8], Mendes et al. 2007 [9]). The second one is the default calibration that may not represent the actual value of suction. (e.g. Irmak \& Haman 2001 [10]; Thompson et al. 2006 [8]; Cardenas-Lailhacar \& Dukes 2010 [11]; Ganjegunte et al. 2012 [12]; Chávez et al. 2011 [13]).

The use of GMSs for civil engineering practices can be said to be still in an early stage when compared with its use for agricultural purposes. Note that its use in engineering works can involve life risk. Studies using GMSs as instruments for suction monitoring in engineering works advanced mainly in themes such as landslides and slope stability (e.g. Mendes 2008 [8]; Napolitano et al. 2016 [14]; De Vita et al. 2018 [15]), stability of temporary trench (Whenham et al. 2007 [16]) and also embankments monitoring (Bicalho et al. 2018 [17]). Furthermore, some tests have already been carried out on the use of GMSs for estimating the soil water retention curve both in laboratory (Chard 2005 [18]) and in field (Jabro et al. 2009 [19]). However, questions associated with the long-term stability of GMS calibration functions, besides its sensitivity to soil salinity, still allows that criticisms regarding to the reliability of suction estimates performed by GMSs continue to be made (Fredlund et al. 2012 [20]).

\footnotetext{
* Corresponding author: danilo.vettorello@gmail.com
} 
Considering the information presented, initiatives that try to understand GMS responses are still desirable. Besides their limitation in the estimation of $\psi$ as an indirect method, their relatively inexpensiveness (Ley et al. 2004 [6]), robustness, and also simple handling characteristics turns them natural candidates for appropriate equipment for continuous in situ suction measurement of civil engineering works. Aiming to contribute to the knowledge about GMSs in suction measurement, this study presents a laboratory experiment comparing GMS measurements with the ones provided by an ordinary tensiometer (i.e. a direct suction measurement method).

\section{Materials and Methods}

The laboratorial experiment performed consisted in monitoring suction values before and after a soil wetting procedure by means of Watermark 200SS sensors with default calibration and an ordinary vacuum tensiometer.

A gneiss residual soil was initially sampled from the experimental site of the Universidade de São Paulo in the city of São Paulo (southeast Brazil). As a characteristic, these residual soils are composed mainly by sandy silts derived from the weathering process of the Embu Complex (Precambrian) gneiss rocks (Lemos \& Marinho (2018) [21]). Since residual soils tend to present heterogeneities, the sampled material was let to dry under ambient conditions, then crushed, mechanically mixed and sieved (\#4 - $4.75 \mathrm{~mm})$. The resultant material was composed mainly by silt $(\cong 78 \%)$ and sand $(\cong 22 \%)$ particles as presented by Orlando (2015) [22].

A wooden box with internal dimensions of $27.5 \mathrm{~cm}$ by $27.0 \mathrm{~cm}$ and $28.5 \mathrm{~cm}$ height was built to act as the container for soil compaction. Additionally, the internal faces of the wooden box were painted with acrylic paint aiming to offer some buffer against water absorption. The soil previously dried and homogenized was then rehydrated and homogenized at a gravimetric water content of $27.2 \%$, which based on the soil water retention curve (SWRC) presented by Orlando (2015) [22], should return a matric suction value of about $100 \mathrm{kPa}$. Finally, the material was carefully compacted inside the wooden box up to the height limit of $25.0 \mathrm{~cm}$, resulting in a dry specific weight $\left(\gamma_{\mathrm{d}}\right)$ of $12.6 \mathrm{kN} / \mathrm{m}^{3}$.

During the controlled compaction process, three Watermark 200SS sensors were installed at different depth, these being $6.0 \mathrm{~cm}(\mathrm{~S} 1), 12.5 \mathrm{~cm}(\mathrm{~S} 2)$ and $18.9 \mathrm{~cm}$ (S3) from the surface of the compacted soil. The default Watermark 200SS calibration with no temperature control was adopted, which means using the Shock et al. (1998) [4] function at a temperature of $24^{\circ} \mathrm{C}$.

The schematic representation of the physical model used in the laboratory, as well as the sensors arrangement, are presented in Figure 1. Before its installation, the GMS was put under water overnight and then allowed to dry for about $8 \mathrm{~h}$ and re-soaked overnight. The GMS was placed while the soil was compacted. An ordinary analogic tensiometer was installed at the middle height of the box (i.e. $12.5 \mathrm{~cm}$ ), between Watermark sensors $\mathrm{S} 1$ and $\mathrm{S} 2$. The tensiometer was chosen to be the suction measurement reference sensor, since it is a direct and more accurate method. After compaction, the top of the box was sealed using aluminum foil aiming to reduce water evaporation.

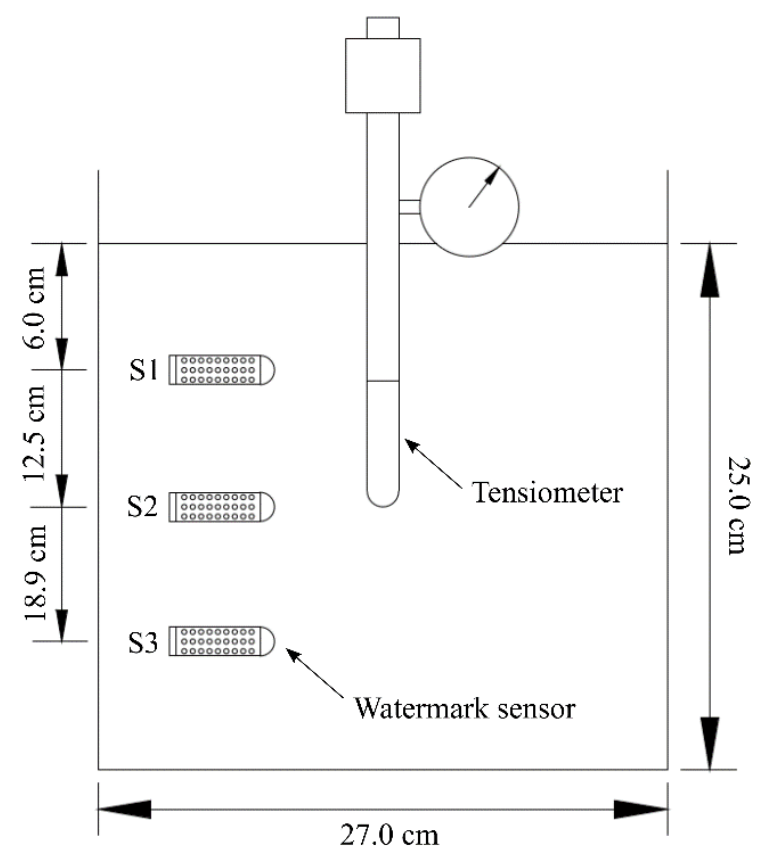

Fig. 1. Schematic representation of the physical model and arrangement of the sensors.

The system was let to rest for about $120 \mathrm{~h}$ promoting pore water pressure equilibrium of the compacted soil as well as equilibrium of Watermark sensors, which would need a longer time for stabilization than the tensiometer. The suction values were registered continuously and automatically by the Watermark 200SS system every 5 minutes. A tensiometer (T1) was installed about $3 \mathrm{~h}$ after the compaction. The tensiometer readings occurred systematically over the first 2 hours. Sixty hours later, the reading was $67 \mathrm{kPa}$, but the tensiometer presented a great amount of air. A new tensiometer (T2) was installed $98 \mathrm{~h}$ after the beginning of the experiment.

The wetting procedure consisted of a direct and slow pouring of $320 \mathrm{ml}$ of water over the compacted soil. This procedure was carried out after almost $120 \mathrm{~h}$ of the soil compaction and monitored for 14 days after the water was placed over the soil. The results of the equilibrium period, prior to inundation are analyzed next, together with the reaction of the sensors to the infiltration of water.

\section{Results and discussion}

\subsection{Initial monitoring}

During the compaction of the soil within the box, the GMS was already registering the suction. The tensiometer was installed after the compaction was concluded. The monitoring of the GMS (S1, S2 and S3) and of the tensiometers ( $\mathrm{T} 1$ and later $\mathrm{T} 2$ ) are presented in Figure 2 
for the first $120 \mathrm{~h}$ after the soil compaction procedure. Tensiometer T1 was installed about $3 \mathrm{~h}$ after the first record of the GMS.

Figure 2 presents the increase in suction with time for the GMSs and tensiometers. For the first six hours, the rate of increase in suction of GMS S1 and S3 was approximately $7 \mathrm{kPa} / \mathrm{h}$. With GMS S2, with a higher rate of $9 \mathrm{kPa} / \mathrm{h}$. After that, the rate dropped to approximately $0.2 \mathrm{kPa} / \mathrm{h}$ for all GMSs.

The measurement with the tensiometer was performed during the first two hours and the rate of increase in suction in the first 5 minutes was $400 \mathrm{kPa} / \mathrm{h}$. Unfortunately, the next reading for the tensiometer was 60 $\mathrm{h}$ after the beginning of the test and the system presented a large amount of air, registering a suction of $66 \mathrm{kPa}$. The results suggest that the system was not completely sealed, since suction continued to increase without any indication of stabilization.

As can be seen in Figure 2, after 120h, the deepest GMS sensor (S3) registered the lowest suction value while the most superficial one (S1) recorded a lower suction than the middle sensor (S2). This is an unexpected behavior and suggests that, at least for small dimensions models, as the one analyzed, the expected gradation of suction values with depth (i.e. higher at the top and lower at the bottom) may not be properly detected by GMS. The maximum difference registered between GMS sensors was of about $10 \mathrm{kPa}$ (S2 and S3).

The average suction registered by the GMS before the water pouring stage was of about $67 \mathrm{kPa}(\mathrm{t}=120 \mathrm{~min})$.
When comparing the value tensiometer $\mathrm{T} 2$ gave at the same time (i.e. $\cong 72 \mathrm{kPa}$ ), it was almost the same as that registered by GMS S2, albeit $8 \%$ and $14 \%$ lower than GMS S1 and GMS S3, respectively.

Figure 3 presents the soil water retention curve (SWRC) for the soil obtained by Orlando (2015) [22] and the suction measured by the tensiometer and GMS (average value) when $t=120 \mathrm{~min}$ as the compaction water content in the present experiment. The value plots are observed to be below the SWRC. It may be a point at a scanning curve, between the primary drying curve and the primary wetting curve.

\subsection{Monitoring the wetting process}

Figure 4 presents the data obtained after the pouring of $320 \mathrm{ml}$ of water on top of the compacted soil, as described before. Water infiltrates slowly and each sensor detected it at different time. The time sensors detect water was defined here as the time needed for a $1 \mathrm{kPa}$ suction drop after the water pouring. The reaction of the tensiometer (T2), located below $6 \mathrm{~cm}$, was practically instantaneous, being less than $5 \mathrm{~s}$. This may suggest a preferential flow between the tensiometer tube and the soil. For the GMS, as expected, the deeper was the sensor, the longer was the time it needed to detect the water, since the water flux is ruled by the soil water permeability. It varied from 2 hours $(\mathrm{S} 1 \mathrm{at} 6.0 \mathrm{~cm})$ to about $3 \mathrm{~h}(\mathrm{~S} 3$ at $18.9 \mathrm{~cm})$ as can be seen in Figure 5, which highlights the first 30 hours after the water pouring.

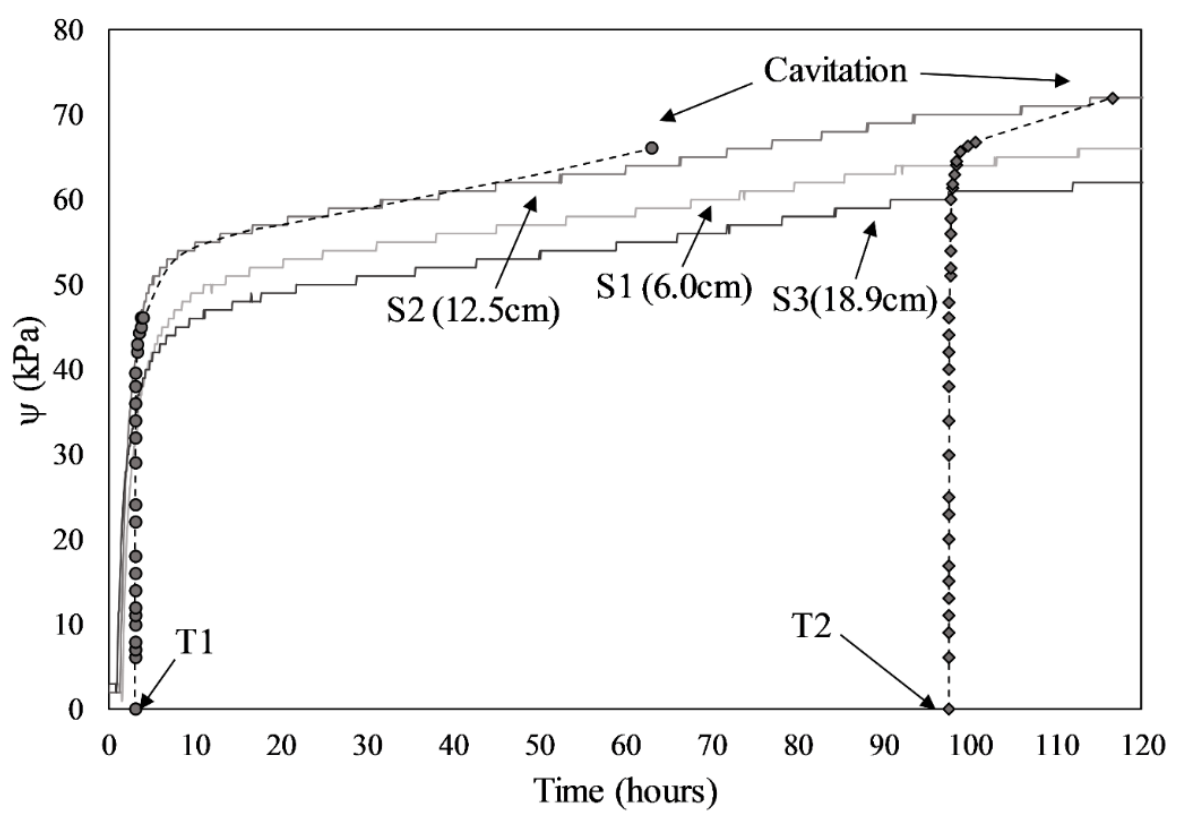

Fig 2. - Time response before the wetting procedure 


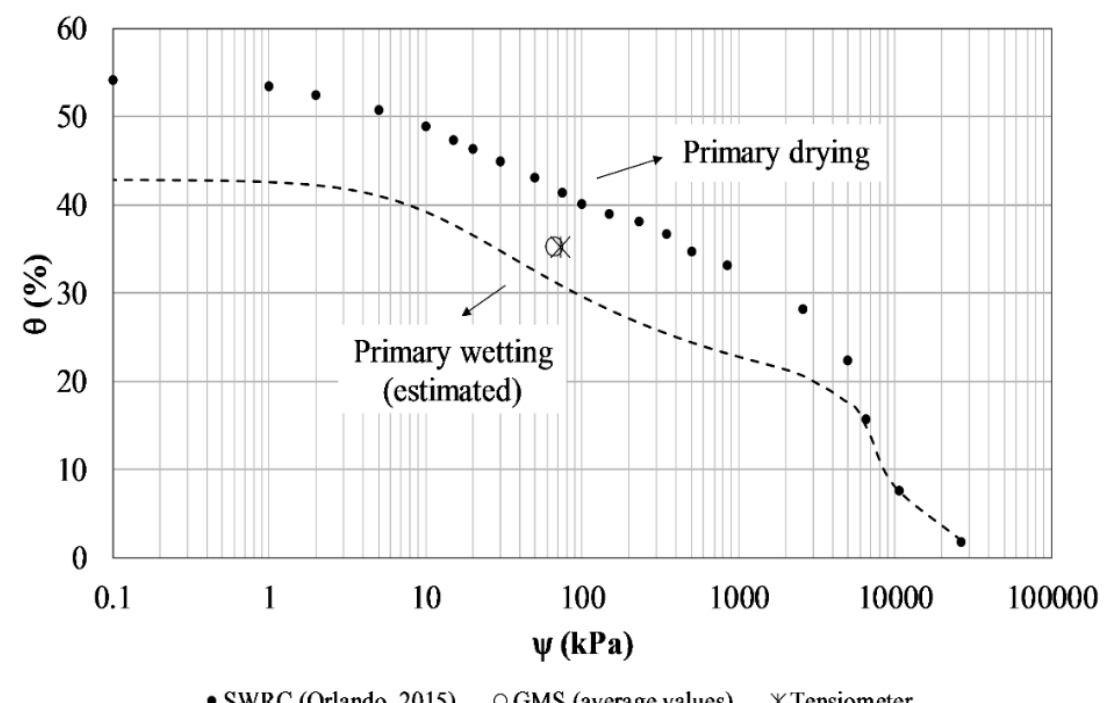

Fig. 3. Soil water retention curve detailing

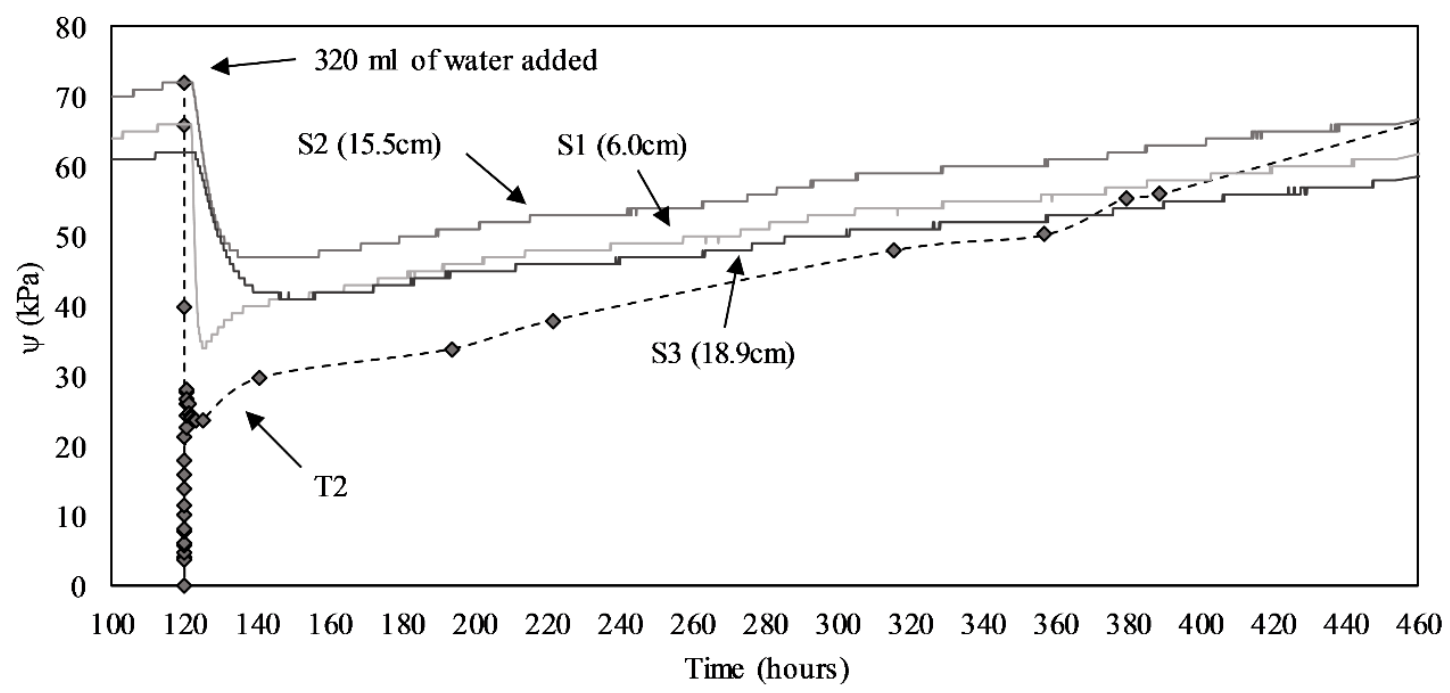

Fig. 4. Suction comparison during the wetting procedure

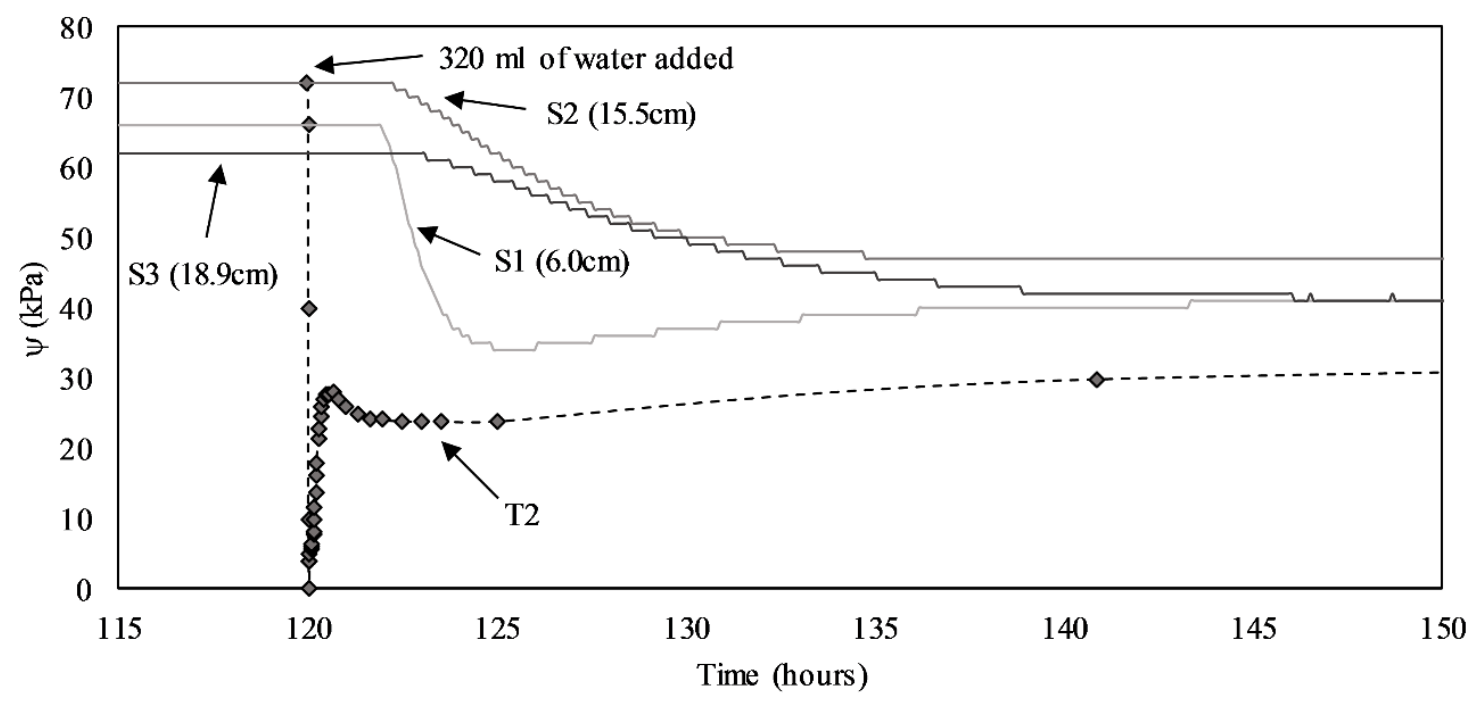

Fig. 5. Sensors reaction after the first minutes of water pouring 
As can be seen in Figure 5, the most superficial Watermark sensor $\mathrm{S} 1(6.0 \mathrm{~cm})$ registered $34 \mathrm{kPa}$ as the lowest suction value after water pouring, while sensors $\mathrm{S} 2$ $(15.5 \mathrm{~cm})$ and $\mathrm{S} 3(18.9 \mathrm{~cm})$ registered $47 \mathrm{kPa}$ and $41 \mathrm{kPa}$, respectively. The time for the GMS S1 to reach its lowest suction value was observed to be approximately $5 \mathrm{~h}$, while sensors S2 and S3 took $15 \mathrm{~h}$ and $26 \mathrm{~h}$, respectively. The minimum suction values registered could imply that the soil would not saturate at those points, since the air entry of the soil is lower than these values. Tensiometer (T2), however, almost immediately dropped to about $0 \mathrm{kPa}$ and, as quickly as before, returned to $24 \mathrm{kPa}$.

Based on what has been presented, we can say that there is a blind zone in the monitoring with the GMS when the topic is the minimum suction value the soil could reach during a water infiltration process. The time response to water detection of GMS is of the order of $2 \mathrm{~h}$. That is, the sensor only detects the variation in suction due to the presence of water after $2 \mathrm{~h}$ of the effective reduction. Furthermore, the two-hour response time does not mean that the sensor already measures the actual suction value, but only stared the process of registering any suction change.

Preliminary numerical analyses for the experiment suggests that the time for sensors S1, S2 and S3 to detect suction reduction due to water would be of $0.5 \mathrm{~h}, 4 \mathrm{~h}$ and $12 \mathrm{~h}$, respectively. However, the numerical analysis nowadays requires adjustments and will be presented in future projects.

\section{Conclusion}

The main conclusions of the study are summarized as follows:

-The response time of GMS is of at least 2 hours. It suggests that Watermark may not be suitable for instant suction measurement or to short-term investigation of engineering works. This is valid especially for situations of risk to human life, such as stability of slopes in urban areas, where this information would be used to trigger emergency evacuations.

-After the GMS stabilization, however, the suction recorded may be quite similar from that recorded by the tensiometer even with no specific calibration or temperature monitoring. It suggests that, even a "direct from box" GMS utilization may bring satisfactory results in suction measurements if the stabilization time is respected. This may be useful for long-term investigation of engineering works.

\section{Acknowledgements}

The authors would like to thank the Coordenação de Aperfeiçoamento de Pessoal de Nível Superior - Brasil (CAPES - Coordination for the Improvement of Higher Education Personnel | Finance Code 001), which partly financed this study.

\section{References}

1. D. Fredlund. (2006). Unsaturated soil mechanics in engineering practice. J. Geotech. Geoenviron. 132: 3 , 286-321, doi: 10.1061/(ASCE)10900241(2006) 132:3(286).

2. A. Ridley \& J. Burland. (1993). A new instrument for the measurement of soil moisture suction. Geotechnique. 43: 2, 321-324, doi: 10.1680/geot.1993.43.2.321.

3. N. Jovanovic \& J Annandale. (1997). A laboratory evaluation of Watermark electrical resistance and Campbell Scientific 229 heat dissipation matric potential sensors. Water SA. 23: 3, 227-232.

4. C. Shock, J. Barnum, M. Seddigh. (1998). Calibration of Watermark soil moisture sensor for irrigation management. Proc. Int. Irrig. Show, San Diego, California, USA, 139-146.

5. I. McCann, D. Kincaid, D. Wang. (1992). Operational characteristics of the Watermark model 200 soil water potential sensor for irrigation management. Appl. Eng. Agric. 8: 5, 603-609, doi: 10.13031/2013.26131.

6. T. Ley, R. Stevens, R. Topielec, H. Neibling. (2004). Soil water monitoring and measurement. $P N W 475$ A Pacific Northwest Publication, Washington, State University, Washington, 1-35.

7. R. Muñoz-Carpena, M. Dukes, Y. Li, W. Klassen. (2005). Field comparison of tensiometer and granular matrix sensor automatic drip irrigation on tomato. Horttechnology. 15: 3, 584-590, doi: 10.21273/HORTTECH.15.3.0584.

8. R. Thompson, M. Gallardo, T. Agüera, L. Valdez, M. Fernandez. (2006). Evaluation of Watermark sensor for use with drip irrigated vegetable crops. Irrig. Sci. 24, 185-202, doi: 10.1007/s00271-005-0009-5.

9. R. Mendes. (2008). Estudo das propriedades geotécnicas de solos residuais não saturados de Ubatuba (SP). PhD thesis, Universidade de São Paulo, São Paulo, Brazil, 1-236, doi: 10.11606/T.3.2008.tde-02022009-175315.

10. S. Irmak \& D. Haman. (2001). Performance of the Watermark granular matrix sensor in sandy soil. Appl. Eng. Agric. 17, 787-795, doi: 10.13031/2013.6848.

11. B. Cardenas-Lailhacar \& M. Dukes. (2010). Precision of soil moisture sensor irrigation controllers under field conditions. Agr. Water Manage. 97, 666-672, doi: 10.1016/j.agwat.2009.12.009.

12. G. Ganjegunte, Z. Sheng, J. Clark. (2012). Evaluating the accuracy of soil water sensors for irrigation scheduling to conserve freshwater. Appl. Water Sci. 2, 119-125, doi: 10.1007/s13201-012-0032-7.

13. J. Chávez, J. Varble, A. Andales. (2011). Performance evaluation of selected soil moisture sensors. Proc. of the $23^{\text {rd }}$ Annual Cent. Plains Irri. Conf., Burlington, Colorado, USA, 29-38. 
14. E. Napolitano, F. Fusco, R. Baum, J. Godt, P. De Vita. (2016). Effect of antecedent-hydrological conditions on rainfall triggering of debris flows in ash-fall pyroclastic mantled slopes of Campania (southern Italy). Landslides. 13, 967-983, doi: 10.1007/s10346-015-0647-5.

15. P. De Vita, F. Fusco, R. Tufano, D. Cusano. (2018). Seasonal and event-based hydrological and slope stability modeling of pyroclastic fall deposits covering slopes in Campania (Southern Italy). Water. 10, 1-23, doi: http://dx.doi.org/10.3390/w10091140.

16. V. Whenham, M. Vos, C. Legrand, R. Charlier, J. Maertens, J. Verbrugge. (2007). Influence of soil suction on trench stability. In: T. Schanz (eds.) Experimental unsaturated soil mechanics. Springer Proc. in Physics. 112, 495-501, doi: 10.1007/3-54069873-6_49.

17. K. Bicalho, Y. Boussafir, Y. Cui. (2018). Performance of an instrumented embankment constructed with lime-treated silty clay during fouryears in Northeast of France. Transp. Geotech. 17, 100-116, doi: 10.1016/j.trgeo.2018.09.009.

18. J. Chard. (2005). Watermark soil moisture sensors: Characteristics and operating instructions. Utah State University. 1-8.

19. J. Jabro, R. Evans, Y. Kim. (2009). Estimating in situ soil-water retention and field water capacity in two contrasting soil texture. Irrig. Sci. 27, 223-229, doi: 10.1007/s00271-008-0137-9.

20. D. Fredlund, H. Rahardjo, M. Fredlund. (2012). Measurement and estimations of state variables. In: D. Fredlund et al. (Eds) Unsaturated soils mechanics in engineering practice. Wiley, New Jersey, USA, 109-183.

21. M. Lemos \& F. Marinho. (2018). Caracterização geológico-geotécnica do solo residual proveniente de gnaisse migmatítico do Complexo Embu, São Paulo, SP. Anais do XIX COBRAMSEG, Salvador, Bahia, Brazil.

22. P. Orlando. (2015). Avaliação experimental da interação solo coesivo-fita polimérica sob condições de teor de umidade variáveis. MA Dissertation thesis, Universidade de São Paulo, São Paulo, Brazil, 1-213, doi: 10.11606/D.3.2015.tde-10112015-113843. 